\title{
Policies for the Knowledge Economy: Knowledge Discourses at Play
}

Tara Fenwick, University of British Columbia

This chapter examines diverse discourses of knowledge embedded in state policies set forth specifically to mobilize lifelong learning for the global knowledge economy. The discussion draws from the literature as well as examples of federal policy documents in Canada related to its Innovation Strategy launched in 2002. At least two broad policy directions have been at play in these policy documents. One continues to emphasise skill acquisition in a conventional deficit-oriented, individualist and universalist model of work education, where the educational goals are upskilling through control and measurement. The other urges innovation as the prime mover of the new economy, where the goals are formulating (and attracting) a 'creative class' through environments conducive to invention. It is suggested that, rather than creating the bifurcated skill economy that some have argued, these trajectories actually appear to create distinct but overlapping knowledge scapes or networks. These networks contain fundamental ambiguities and discontinuities about the meaning and value of knowledge in a knowledge economy, spaces which may open possibilities for educators.

The chapter proceeds in three sections. The first examines diverse notions of knowledge and skill that have proliferated in policies and critical responses linked to the knowledge economy discourse. The second discusses specific examples of federal policies in Canada that illustrate many of these currents. The third section discusses the ambiguities and tensions apparent in such policies, showing the play of knowledge discourses that invite openings for alternate conceptions of workplace learning and the knowledge economy.

\section{Knowledge in the Knowledge Economy}

Since the 1996 OECD statement that "[k]nowledge is now the driver of productivity and economic growth" (p. 4), knowledge discourses have proliferated in economic policy documents of developed countries. These knowledge discourses tend to promote a generic and non-contextualized capacity to learn, to use tacit (know-how) knowledge to transform codified knowledge, to innovate with technology, and to form knowledge networks (Robertson, 2005). The focus has been on both defining knowledge for knowledge capitalism and determining the critical conditions for the production of knowledge. The goal is to articulate specific directions for human capital development (e.g. skills) on the one hand, and innovation (e.g. commercializable ideas) that will ensure a nation's competitive position in the global knowledge economy.

Innovation in particular has been frequently cast as a critical form of knowledge in the knowledge economy, with federal policies urging a focus on innovation in research and lifelong learning. For example, Canada's Innovation Strategy launched by the federal Human Resources and Development Commission in 2002 is similar to Australia's higher education reform announcing that ' $[\mathrm{r}]$ esearch and innovation play a vital role in building Australia's competitive strength in a global knowledge-based economy (Nelson 2003 p. 31). A comprehensive national program of research funding in Canada called Initiatives for the New Economy simultaneously targeted four areas of education, lifelong learning, management and entrepreneurship. The program specifically invited studies that addressed questions such as, What conditions and 
factors stimulate innovation in firms and organisations? What business practices underpin innovation? What significant factors affect the relationships between innovation and organisational change? (INE, 2001). In 2002, the presidents of Canadian universities entered a framework agreement with the federal government to increase their funding through the Canada Foundation for Innovation in return for universities' agreement to double the amount of research for innovation conducted in their universities and triple their commercialisation performance by 2010 (Briskin, 2002). As the Innovation Strategy declares, 'Academic institutions have an essential role to play in strengthening Canada's innovation performance. They have acknowledged that they too must continue to strive for excellence and rise to the innovation challenge' (HRDC, 2002, p. 22).

Innovation is defined almost exclusively in economic terms, as 'both the creative process of applying knowledge and the outcome of that process' (HRDC 2002, p. 19). There is authority and inevitability that statements that in 'the innovative race to be run', we must measure 'innovation outcomes' and 'innovation performance' in the 'innovation system' which connects learning, education, researchers, investors and entrepreneurs. The overall position is that 'in today's knowledge-based economy, the importance of innovation has increased dramatically' (HRDC 2002, p. 19). A diffusion of popular texts promoting innovation have accompanied such policy rhetoric. In North America for example, a particularly widely-cited thesis was advanced by Harvard economist (recently recruited to the University of Toronto) Richard Florida in The Rise of the Creative Class (2002). In it, Florida claimed that economic growth depends on a 'supercreative core' of workers, about $30 \%$ of the labour force, who value creativity, individualism, difference and merit. He urged cities to create hip conditions attracting these elite innovators who want to be quickly accepted and participate culturally on their own terms.

While innovation appears to be the dominant preoccupation in such texts, an agenda of upskilling existing workers, particularly those considered to be vulnerable, continues to be emphasized as an urgent challenge in North America, Europe and Australia. Canada's Essential Skills Initiative (HRSDC, n.d.) stresses development of generic, 'soft' skills of communication, very similar to those promoted in the UK Core Skills Programme. The UK white paper 21st Century Skills; Realising our Potential (2004) focused on integrating government bodies, trainers, educational institutions and employment settings in a strategy to develop skills in communication, information technology, numeracy, working with others, and problem solving. Skill in these policies has, as Valentin (2005) points out, become increasingly flexible, social and transferable, more like personal traits than functional or industry-specific skills.

'Skill' is ubiquitous, the term being applied to such diverse phenomena as reading, writing, problem-solving, learning, team work, salesmanship, marketing, presentation, perseverance, motivation, enthusiasm, attitude, corporate commitment, customerorientation, stress management .......skill means whatever employers and policy-makers want it to mean (Payne 2000:361).

The language of such documents invokes demands for both innovation and skill development, wedded with injunctions of continuous learning and success in a globalised economy -- even weaving in social values of inclusion and equity -- as though these are 
all naturally aligned and uncontested domains.

\section{What Counts as Knowledge? Bifurcations and Exclusions}

Some educationists, according to Lloyd and Payne (2003), have responded enthusiastically to these knowledge-economy discourses. Their 'seduction' is the promise of a workforce that will be better educated and less hierarchical, as the deep-rooted divides between academic/vocational education and mental/muscle labour will supposedly dissolve in a post-Fordist knowledge-based workplace. Educationists, they show, are attracted to the possibility that all workers, across race, gender and class, can develop and exercise high-level skills of communication, analysis and creativity, and become involved in wider contexts of learning in which they take real responsibility for their learning. If this possibility becomes realised, then power relations governing workplaces would shift to reward those with intellectual skills rather than simply 'those at the top'. Other educationists have argued that, if decoupled from the economy, the vision of highly-skilled, learning-oriented and creative citizens can lead to an actively democratic and socially just society (Avis 2000, in Lloyd and Payne 2003).

However, the emphasis on (technological) innovation and the fusion of learning/labor/education to innovate for economic growth has also spurred critique from many educational commentators. A common complaint has focused on the repressive effects of the continuous learning mantra, yoking human subjects to the market in a relentless, lifelong and lifewide human resource development project(Fenwick, **). Another critique focuses on problematic conceptions of innovation. In their analysis of Australia's innovation strategy for the knowledge economy, Kenway et al. (2006) point out its reliance upon a flawed techno-determinism: a Schumpeterian approach to innovation as preceding and 'driving' the economy. They argue that in this knowledge configuration, universities become tightly coupled with business in ways that repress the knowledge 'gift economy' where ideas flow freely. Knowledge workers are problematically configured as 'techno-preneurs': entrepreneurial subjects, networked and manipulating knowledge competitively for material gain.

Still others have argued that the emphasis on knowledge and particularly innovative knowledge, within an economy that continues to rely on low-skill labour, has created a high-skill/low-skill divide. Work organizations on the whole are still far from providing post-Fordist conditions of knowledge work, and still tend to segregate knowledge production work such as innovation from material production (Brown et al., 2001; Lloyd and Payne, 2003). A bifurcated economy has resulted, claim these commentators, where any changes in work organisation or availability of high skill work has touched only a small minority of employees. Some argue that this bifurcation functions globally, and is reinforced by education provisions. Elite education of high skills development and social capital can increase integration and participation in global economy, but also promote worker migration to wealthy regions (Tikly, 2001). Basic education and low-skills training can improve conditions for the poor but also create wider exclusionary divides within and across regions. Education generally can legitimise an existing global order that, as Stiglitz (2002) claims forcefully, garners a disproportionate share of benefits for 
the West at the expense of the developing world, but education also fuels resistance by providing forum and focus for critical correspondence with the status quo.

Excluded from innovative work are those who may lack the tools, resources, environments and encouragement to have developed capacity to be sufficiently innovative. Florida's (2002) claim that a new 'creative class' is emerging which cities should entice and encourage suggests an ignored underclass - not just those relegated to jobs that suppress innovation, but also those whose skills and activity are not recognized as valued knowledge. Excluded, for example, are traditional and Indigenous knowledges, and local knowledge in workplaces created through workers' everyday adaptations and translations - knowledge that is widespread and often invisible. Farrell and Fenwick (2007) urge critical analysis of how knowledge discourses that celebrate continuous learning, innovation and collaborative partnerships have become naturalized and assimilated into common notions of what counts most as work knowledge. These valuations subjugate other forms of knowledge such as embodied craft knowledge or collective ecological knowledge. The result of these pressures for continuous innovation, as Field (2000) notes, are widening inequality and exacerbating market assaults on fragile environments and communities.

\section{Ambiguities - Innovation, Skill and Knowledge}

Besides these problems of exclusion, inequality, economic bifurcation and technodeterminism produced by innovation-centric knowledge-economy discourses, there is another central issue at the heart of such policy rhetoric. That issue is the ambiguity about what exactly constitutes innovation and skill, and knowledge more broadly for the knowledge economy.

In organization and management studies literature, innovative knowledge and skill is granted central importance given the uncertain economy: 'those organisations that prove to have superior abilities to manage exploration will be better able to adapt to changing circumstances' (McGrath 2001, p. 119). Innovation tends to be conceptualized in two ways. First, as a process of research and development separated from everyday work processes, innovation is intended to develop the new products that ensure a competitive edge, or improve the efficient production and distribution of these commodities. Second, innovation as continuous ongoing improvement throughout the organisation has been increasingly a central interest, with a focus in organizational learning strategies upon stimulating and supporting innovation, diffusing, integrating and institutionalising it within everyday practice (Crossan et al., 1999). Writers advance theories about the processes of innovative learning, seeking ways of removing so-called barriers to innovation, and encouraging workers' experimentation, risk-taking, and variance-seeking (Crossan et al., 1999).

The larger enunciations and critical analyses of 'innovation' as being essentially the production of technological knowledge tend to overlook these embodied, situated forms of improvisation and improvement that bubble forth in everyday work of the global economy (Farrell and Fenwick 2007). In fact, the growing drift to implement international standards of operation often prohibits workers' improvisatory adaptations of routines. Workers tend naturally to engage in innovative activity all the time, or 'common 
knowledge' - precisely the sort of ongoing experimentation, adaptation, and local solutions required to make foreign tools and processes actually work in particular contexts.

Furthermore, argues Farrell (2006), the knowledge most promoted in many workplaces is not innovation but new textual literacies: mediating audit and management texts, communicating in self-directed work teams, and managing electronic texts that transports knowledge across contexts. Capacities such as image-management and self-presentation are often more evidently at play than knowledge generation in negotiating the multiple networks, virtual, social and material, that constitute everyday work activity (Thompson et al. 2001). These are arguably intellectual 'high skills', not the manual or standardized low-skill routines that critics have complained continue to dominate the available jobs in the so-called knowledge economy. However, these textual literacies are themselves routinized and highly regulated. They are not the improvisatory, free forms of creativity that innovation discourses gesture towards.

Recognition of knowledge and 'innovation' is a critical dynamic, particularly given the provisional, interactive and mobile nature of much innovative knowledge alongside certifiable vocational skill and codified scientific knowledge in workplaces. When does an invention become accepted and performed as an innovation in a given community, and in whose eyes? As Engeström (1999) pointed out, what is pronounced novel rests on community values, perceptiveness, historically shaped attitudes, expectations and desires. The uptake of innovations often depends less on the nature, quality or need for a new process or technology and more upon its complex and unpredictable mediating conditions. Recognition of skill, too, has long been understood to be a political negotiation that is gendered, racialized and classed. The emphasis on 'skill' development continues to label workers as categorically 'skilled' or 'unskilled', based on assumptions that the ability to perform certain activities can be standardised, measured and added where missing. The politics of who knows what is 'skill' becomes buried in such practices. This affects most profoundly not only those moving from one vocation to another as employment opportunities shift, but also the migrant professional workers seeking credentialisation in host countries. Furthermore, as Sawchuk (2007) shows, alongside the press for workers to be 'upskilled' in technological competencies needed for the knowledge economy, the rapidly changing technologies have deskilled existing work beyond the point of recognition.

Against these more sedimented views of knowledge/skill as static and discrete, whether embedded in the body of a worker or in the product of scientific innovation, is the notion of the knowledge economy as a series of global networks. In the OECD (1996) statement, networks are represented as pipelines necessary to distribute knowledge efficiently, quickly, widely links across regions and sites of knowledge production - to encourage the emergence of innovation. This view conceptualizes differential global networks linking people with organisations and practices in distributed production and supply chains that make new demands on their capacity to produce new knowledge (Farrell and Fenwick 2007). For example, using studies of concentrated knowledge production such as Silicon Valley, Brown and Duguid (2002) show that 'the networked economy is not just a 
technological network carrying digital information, but a social network supporting the creation of human knowledge' (p. 436).

A network metaphor can represent more entrenched, immutable and prescriptive networks as well as more open, diffused and exploratory linkages. But overall, a networked understanding of knowledge as mobile and uncontainable announces its distinction from other tradeable commodities in an advanced industrial economy. Olssen and Peters (2005) point out that, as capital, knowledge has increasing rather than decreasing returns- rather than becoming more scarce, knowledge grows through sharing and application. Furthermore location doesn't matter given how knowledge travels through technology: knowledge 'leaks' and spillover (e.g. general principles developed along with specific innovations) make it almost impossible to protect or control. Similar knowledge has different value in different contexts; and some knowledge is easily produced and distributed while some remains embedded in local activity. In this sense, knowledge generation depends upon improvisation, sharing and mobility, which depends upon social capital, conditions of trust and equity.

Yet these formulations are not easily reconciled either with the human capital/skills development orientation or with the drive to commercialise innovative knowledge production. Overall, while there seems to be almost universal agreement that the global economy is increasingly knowledge-based, there is no clear agreement about what constitutes 'knowledge', who or what participates in such knowledge, or how they make it or use it.

\section{Canada's Federal Policies for the Knowledge Economy}

Turning to specific examples of policy, this argument will be developed through a discourse analysis of initiatives introduced by the government of Canada. In these we can see how policies for the knowledge economy embed discourses representing knowledge as flowing in relational collaboration alongside conceptions of knowledge as predetermined and contained in discrete skills located within individuals. Innovation floats as both emergent and bounded, as process as well as property. Ambivalences open around program objectives, which tend to target skill deficits particularly of pre-identified populations of disadvantage, while announcing the need to foster conditions for creativity.

The analysis is premised upon documents circulated through three federally-funded programs in Canada: the Essential Skills and Workplace Skills Initiatives, and the Innovation Strategy. These documents included web-based statements of the program's goals, rationale, activities and intended outcomes, as well as their calls for proposal through which program and research funding for workplace learning initiatives are distributed. It is important, particularly when examining ephemeral documents such as calls for proposal, to realize that while discourses are manifested partly through texts, that they are much broader and include social and cultural structures and practices that cannot be glimpsed through particular texts even though they inform textual production and consumption (Fairclough, 1992). However, texts are valuable artefacts of discursive practices, revealing particular signifiers and codes that influence social understandings and behavior. 


\section{Discourse Analysis of Policy Documents}

According to Fairclough (1992), whose methods of critical discourse studies appear useful for analysing policy documents that mediate knowledge production in the economy, everyday lives are increasingly textually mediated. Critical discourse analysis explores how different discourses work in these practices. Janks (1997) argues that close examination of texts and interactions in policy contexts is helpful in identifying prevailing discourses, how and by whom they are produced, taken up or resisted, interpreted and acted upon, and what results from discursive interactions.

In analysing diverse discourses involved in knowledge-mediating documents such as federal policy statements, then, one adopts what Patterson (1997) has called a 'condition of doubt' to trace power relations evident in their interaction: which discourses are granted dominance, which are suppressed or nominalized, which become invisible, and which struggle for voice or resist. These tensions can be expected to occur within as well as between discursive formations. For Fairclough (1997), the process of discursive negotiation involves not just conflict but also semiotic hybridity, intertextuality and identity flow. Identification of these dynamics proceeds through detailed analysis of semiotic features of texts and interactions, then examines how they draw in innovative ways on the 'orders of discourse', the shifting discourses and genres in particular relations.

The approach used here drew selectively from methods associated with discourse analysis in an iterative reading of specific aspects of the texts against one another and against their contexts of use, insofar as these are reported in available documents. Certain signifiers, linguistic structures and associated meanings evident in these documents were analysed to explore the different discourses of knowledge that were being promoted, as well as the strategies used to legitimize particular forms of knowledge and particular ways of developing knowledge. Linguistic strategies such as foregrounding (emphasized concepts), backgrounding (omitted or marginalized concepts), and presuppositions (constructions and even appropriation of the reader's values, background knowledge, etc.) were examined (Huckin, 1997). It is important to situate such analysis within the contextual purposes and uptake of the texts. While these dynamics were not examined empirically in this analysis, consideration was given to the ways in which texts functioned within the contexts of federal expectations of knowledge outcomes, and the overall policy contexts such as federal social and economic objectives referred to by the texts.

\section{The Innovation Strategy}

Canada's Innovation Strategy (HRDC, 2002), announced in 2002, foreshadowed all of the initiatives discussed in the remainder of this paper (the Essential Skills and Workplace Skills Initiative, and the Canadian Council for Learning). The Innovation Strategy was premised on the belief that,

Increasingly, success in the knowledge-based economy requires individuals who are creative and who have highly developed problem-solving and communication skills. . By providing opportunities for all Canadians to learn and to develop their skills and abilities, we can achieve our commitment to economic growth and prosperity and demonstrate our social values of inclusion and equality. (HRDC, 2002, p. 6) 
This blurring of social inclusion commitments with human capital development was combined with emphasis upon innovation. Citations of literacy rates and productivity studies were linked to urgent imperatives in rhetorical strategies that invoked national insecurities: 'Canada's innovation performance is weak, and this is affecting productivity levels and economic performance ... Canadians must become more innovative. Improvements in our innovative capacity are critical to productivity growth and wealth creation' (HRDC, 2002, p. 21, 29).

The Innovation Strategy was presented in two documents. Achieving Excellence: Investing in People, Knowledge and Opportunity (Industry Canada 2002) was broadly concerned with research capacity-building. Knowledge Matters: Skills and Learning for Canadians (HRSDC 2002) focused on lifelong learning for work and human capital development. The dual positioning of these documents, argue Metcalfe and Fenwick (2008), reflected the bifurcated agenda argued by others (e.g. Brown et al., 2001) that separated "skills" from "innovation" while connecting both in a single knowledge production strategy.

Yet a closer reading of Knowledge Matters reveals both discourses at play, alongside rhetoric of social inclusion. On the one hand, it states injunctions that reflect acquisitional understandings of knowledge as a measurable, trainable skill that is accumulated and centered in the individual. The strategy's stated intentions are:

- to develop "individuals who are creative ... highly developed problem-solving and communication skills"

- to promote "assessment and recognition of previously acquired knowledge" and

- to "ensure Canadians have the tools they need to participate fully in today's knowledge economy" (with particular concerns stated for Aboriginal people, new immigrants and the "low skilled."

Innovation for national competitiveness also figures prominently in this document for workplace learning, although it is often framed as a bounded quality that is located in individuals. The injunction is to obtain individuals possessing this innovative capital:

- seeking “.... greater number of innovative people driving innovation, or applying innovations", and

- attracting and retaining "the highly qualified people required to fuel Canada's innovation performance."

However, the document also contains vocabulary reflecting conceptions of knowledge as reliant upon conditions and structures of work that enable learning. Strategic directions include

- "building learning infrastructure",

- promoting "networks to advance and disseminate knowledge", and generally

- promoting "lifelong learning in the workplace."

This language steps away from viewing innovative knowledge as a pre-determined contained commodity and invokes conceptions of knowledge as networked and shared rather than individualist. Such notions gesture towards a sense of unpredictability, collectivity and perhaps emergence in knowledge generation that is distinct from the notions of specifying, measuring and controlling pre-determined knowledge.

\section{"Essential Skills Initiative" in Canada}


The Essential Skills Initiative, launched by the Canadian federal government for the stated purpose of "creating a more productive workforce" and attracting and retaining "the highly qualified people required to fuel Canada's innovation performance", is well-funded to drive research, practice and policy in workplace learning (HRSDC, n.d.a). Nine skill areas were declared essential in all work, such as document use, numeracy, 'working with people' and 'thinking' skills. All occupations, not just entry-level or low-skill work, are now in process of being 'profiled' to determine the precise mix of Essential Skills required. About 200 jobs in the National Occupational Classification index have now been profiled. An example might be Retail Sales Manager, whose necessary skills have been determined to be Oral Communication, Problem Solving, Decision Making and Working With Others on complexity levels of 2-3 (out of a possible 5). The profiles, accompanying tests and instructional materials are for use by teachers, career counselors and individuals "to know if they have the skills they need to do the jobs they want to do" (HRSDC, n.d.a). Colleges are now advertising their reconstituted programmes, such as Bow Valley's "Building Workplace Essential Skills" classroom course for online delivery, complete with a database and individualised learning plans enabling instructors to track learners' success in mastering Essential Skills. Industry sector councils (30 in Canada including trades, resource sectors such as forestry, and certain professions) have participated in projects to assess individuals and develop their 'Essential Skills' as identified for specific occupations within their purview (HRSDC n.d.a). Employers are reportedly employing the Essential Skills for recruitment, promotion and assessment processes.

\section{| "Workplace Skills_Strategy" in Canada (WSS)}

The "Essential Skills" Initiative has continued to be funded and supported while the Workplace

Skills Strategy (WSS) was launched in 2005 as the "key pillar" program of the federal human resources department. WSS is a large multi-stakeholder-driven (business and labour, not educators or academia) set of programs to which the federal government announced a commitment of $\$ 3.5$ billion over the next five years (HRSDC n.d.b). The assumptions of the strategy are captured in the following statements from the HRSDC website:

Canada's success, and the success of individual Canadians, relies on our economic productivity. And our productivity, in turn, is increasingly dependent on skills and learning ... To continue to prosper as a nation, we must develop value-added activities that focus on innovation, research, and worker skills and qualifications.

Here we see the clear links between learning, innovation and knowledge generation, all framed within a discourse of skills and human capital theory. The goals of WSS are stated to be promoting workplace skills investment, promoting skills recognition and utilization, and promoting partnerships, networks and information. Thus, alongside a continued focus on individual skills development and testing, there is now on the agenda at least a recognition that workplace environment and structures require attention too, and that inclusion is an issue that cannot be simply addressed through an individual's skill levels. So WSS mentions the need to improve apprenticeship opportunities and recognition of immigrants' credentials, remove barriers experienced by aging and disabled workers, and increase workers' access to learning opportunities (HRSDC, n.d.b). 
The WSS funds projects that develop worker skills as well as innovative "tools" for developing worker skills, through competitive bids submitted by partnerships that can include private and public organizations, research institutions, labour groups etc. About $\$ 31$ million was allocated to the first call for proposals; a second call closed on April 182007 and a third call is in drafting process. In other words, significant resources have been made available to fund projects willing to frame themselves according to the HRSDC guidelines.

And what are these guidelines? According to the second and most recent call for proposal, priority will be given to proposals for applied projects that will "develop skills for workers" while demonstrating "lessons learned/best practices" that can apply across contexts (HRSDC, n.d.b). "Impact" must be demonstrated - on employers, employees, stakeholders and workplaces. Projects must be "promising", a term that is not defined. Purposes for the research are provided explicitly. Overall, projects are to develop solutions: "support the adoption, testing and sharing of promising tools and approaches for enhancing..." skills of target groups (HRSDC, n.d.b). In this second call, the target groups were identified to be older workers, low-skilled workers, and newcomers to Canada: populations considered priority because underutilized in the labour market. The two-year timelines for projects are short, and must include realization of all knowledge development outcomes and full dissemination of innovative practices created.

Finally, "partnerships" are emphasized: both for funding purposes (partners or applicants must provide $25 \%$ of the total project budget) and to "secure expertise": applicants are expected to build upon or create new partnerships (HRSDC, n.d.b). However, the nature and meaning of "partnership" and roles of "partners" are not defined beyond these references. This creates an interesting ambiguity when the program is aimed at potential partnering participants across public and private sectors, industry and education, academic and vocationally-oriented organizations,.

\section{Discussion: Tensions and Ambivalences}

These initiatives funded by Canada's federal government potentially can shape workrelated knowledge in particular directions, depending on the degree to which educators and researchers take up their terms in order to solicit resources. The actual programs consist of funding available for projects that combine research with educational strategies to promote workplace learning for a knowledge economy. While this analysis does not examine the extent of this uptake, it is reasonable to assume that the funding available, in some cases in considerable amounts, would attract organizations seeking to increase training provision as well as workplace educators and researchers from universities, private agencies or think tanks.

Project funding is obtained in a competitive application process submitted by partnered organizations. This hands-off strategy of distributing resources for workplace learning relieves the state from specifying and being accountable for any particular strategy for skill development and knowledge circulation. It also removes accountability for ensuring equitable assistance for the most vulnerable individuals and organisations. Projects simply must yield "best" practices and knowledge that can be universalized, which may 
be defined in any terms by applicants. This discourse is based on a 'what works' perspective, in which a central assumption is that what has worked in the past, in a particular context with particular actors, corresponds to what will work in the future, across different actors in unpredictable contexts. As Biesta (2007) points out, this logic is legitimate as the logic of individual practice: that is, a practitioner continuously applies and adapts approaches recalled from past practice, but this application is particular, contextual and fluid. To apply such logic as a basis for knowledge development is to commit a logical fallacy, particularly in context of promoting innovation: what has worked cannot correspond to what will work, only to what might work in certain contexts. Further, what works is recognized very differently in various industrial, public sector, educational and other environments. The problem to be solved by 'what works' may be defined in ways that have little to do with innovative learning opportunities, broader knowledge circulation, workers' well-being, job enrichment, 'high skills' development, or any of the generative possibilities that educationists may have hoped for in a knowledge economy.

Against this 'best practices' discourse, which universalizes and centralizes knowledge, the networked knowledge discourse is about decentralization and circulation. The desire for certainty and control of developing best practices - both practices of material work and practices of learning material work - is thus asserted alongside discourses of knowledge as uncertain and emergent, implied in statements urging creativity and leading edge innovation. Beyond these statements, little direction or allowance for innovation is provided. According to the terms of these initiatives, pursuits that might be linked to innovation are presumably not fundable: exploratory knowledge, workplace experimentation, forms of knowing that open new questions about existing systems, or knowledge that might reconfigure existing frames that continue to define problems and solutions in ways.

Across these documents, certain common signifiers are positioned with emphasis but without much clear definition. Terms such as "innovation", "partnership", and "promising" (that is, projects that indicate "promising" tools or approaches will be given priority) are not clarified. "Promising" can refer to projects that are most innovative, most viable, are most likely to have wide application, or that have the widest scope of solution. "Innovative delivery" of education is encouraged, but also innovation in new solutions and new knowledge. Indeed the Director of WSS admitted that the priority for "innovation" was decreased in the third call for proposals because the HRSDC reviewing staff discovered that they had no clear or consensual meaning amongst themselves regarding what constituted "innovative" projects (personal communication, March 23 2007). "Partner" references, along with "networks", provide no indication of how or why partnerships are to be created for knowledge generation, or what constitutes a 'partnership' beyond diversity (individuals/organizations, human non-human entities, public/private?). Knowledge generation within and across partnerships is left ambiguous - as long as it is linked to innovation and skill development.

A high skill/low skill analysis of these knowledge discourses might posit a separation of innovation from skill, where innovation is understood to be codifiable scientific research 
conducted and disseminated from knowledge-generating institutions, and skill is confined to discrete, low-level competencies in workplaces. But these policy documents do not actually reflect such clear separation. For example statements of innovation appear, albeit conceptualized as both measurable human capital and fluid relational process, in skill documents of the WSS. The Essential Skills measurements embrace all 30,000 of the occupations classified in the national index, including professional sectors and knowledge producers, not just low-skilled or disadvantaged workers targeted for upskilling. Workplace and research institutions are expected to collaborate in projects without clear lines between knowledge producers and knowledge users, where results must be represented in terms of both codified new knowledge and 'knowledge mobilization' such as new skills developed among all partners.

Yet for all the emphasis on innovation and networks of innovation, the actual links of innovation to 'skill' are unclear. While Canada's overall Innovation Strategy emphasizes the importance of creativity, the Essential Skills Initiative - claiming to spell out all the skills necessary for life and work - does not contain a single mention of creativity. No references occur to imagination or the arts. Nor are there references to skills in building networks and partnerships, creating and sustaining collaborations (e.g. for innovation), or the actual skills of generating knowledge. Surprisingly for an innovation strategy, skills of enterprise and entrepreneurism are not included - certainly nothing resembling the technopreneurial subject described by Kenway et al. (2006). Less surprising, skills of critical analysis and advocacy are invisible. But if such policies are intended to separate critical, innovation, scientific knowledge production from workplace 'low skills', it is important to note that material skills of work are also not mentioned, nor do any statements discuss embodied craft knowledge. Instead, most of the essential skills seem to focus on broad literacies such as document use and working with others. These skills are aligned with the new textual literacies discussed by Farrell and Fenwick (2007), which increasingly are required of all workers, the 'creative class' alongside skilled and low-skill workers, to be compliant with the knowledge standards circulating in the global economy.

\section{Conclusion}

In the language of policy documents promoting workplace learning for a knowledge economy, what becomes apparent are the diverse, even contradictory, meanings of knowledge playing across and within these documents. Innovation occupies a central rhetorical position, with claims that knowledge circulating in systems has higher inherent value than that locked in individual heads. Yet individual skills development is also a key value. Thus, the focus to identify and reproduce (and measure) pre-determined knowledge, as 'essential skills' is presented alongside a focus to transform through innovation. Human capital formation, conceiving knowledge as concretized and visible in distinct bodies, is entwined with commitments to promote innovation conceived as mobile, networked knowledge. The knowledge generation that is stated to 'fuel' the knowledge economy is associated with trust, openness and experimentation. These values are encouraged in networks that appear to co-exist with injunctions of performativity, accountability and surveillance fostered by the Essential/Workplace skills initiatives. The projects and interventions sponsored by the skills initiatives focus on increasing discrete 
skills of disadvantaged individuals without apparent acknowledgement of the system constraints and enablers - both the socio-material relations in which skill/knowledge is performed as well as the 'learning infrastructure' of a workplace environment - that are stated to be so important to (innovative) knowledge generation.

Thus, rather than presenting a clear high skill/low skill dichotomy on the one hand, or a regulatory discursive regime on the other, knowledge discourses in such policy documents at best circulate in ways that create ambivalences. While there is pervasive rhetorical commitment to encourage a dynamic of innovation, it remains so ambiguous as to function as little more than an empty signifier. The concomitant discourses of skill are firmly focused upon control and containment of what is already known while gesturing fervently to the need for knowledge that is yet to come. However, the sorts of skills being targeted are so generic as to permit wide interpretation of what knowledge actually counts.

At the heart of these ambivalences in knowledge discourses are compelling uncertainties: uncertainty about the nature of knowledge and how to foster its development and circulation in a knowledge economy; and uncertainty about the forms of knowledge that are actually desired. There is little evidence of a clear ideological agenda from the state promoting particular forms of innovation or technopreneurship. Nor is there evidence of a regulatory regime beyond some diffuse pronouncements unsupported by policy levers or disciplinary technologies. Instead, what seems to have emerged in these knowledge discourses for the economy is confusion. Some may argue this to be evidence of the state's abdication of a responsibility to increase workforce skills. Others, following Žižek (2008), may insist that what is operating is 'everyday ideology' that, in a Marxist analysis, is ultimately creating a perfect equilibrium of high and low skills.

However, where there is uncertainty and ambivalence, there is space to manoeuvre. The vague categories of skill and innovation, and the contradictory meanings ascribed to knowledge, create spaces of possibility. These possibilities may include reframing the more repressive notions of a knowledge economy. They permit a redefining of workplace learning in any number of directions that may interrupt the bifurcated economic structures and promote greater equity, richer knowledge recognition, and wider freedom to participate in knowledge production. These possibilities also invite us to resist the compelling seduction of achieving some control over work-based knowledge, the sorts of control and need for certainty that are evident in the persisting discourses of skill specification and measurement. Instead, the ambivalences and disjunctures among these knowledge discourses beckon us to dwell within uncertainty - even undecidability - as a space in which to reconsider workplace learning and education. Uncertainty, undecidability, and risk, albeit uncomfortable, arguably are central conditions for generating new knowledge and fostering creativity - even, or perhaps especially, among educators.

\section{References}

Avis, J. (2000) Policy talk: Reflexive modernization and the construction of teaching and 
learning within post- compulsory education and lifelong learning in England. Journal of Education Policy, 15(2), 185-199.

Biesta, G. (2007). Why "what works", won't work: Evidence-based practice and the democratic deficit in educational research. Educational Theory 57 (1), 1-22.

Briskin, L. (2002). Faculty expected to triple their commercialization performance. CAUT (Canadian Association of University Teachers) Bulletin. Toronto: York University.

Brown, J. S. and P. Duguid (2002). Local Knowledge: Innovation in the Networked Age. Management Learning 33(4), 427-437.

Brown, P., Green, A., \& Lauder, H. (2001). High skills: Competitiveness and skill formation. Oxford University Press.

Crossan, M.M., Lane, H.W., \& White, R.E. (1999). An organizational learning

framework: From intuition to institution. Academy of Management Review, 24 (3), 522-

537.

Engeström, Y. (1999), 'Innovative learning in work teams', in: Y. Engeström, R.

Miettinen, \& R-L Punamaki (eds), Perspectives on Activity Theory (pp. 377-406), Cambridge University Press, Cambridge, UK.

Fairclough, N. (1992). Discourse and Social Change. Cambridge: Polity Press.

Farrell, L. (2001). The 'new word order'- workplace education and the textual practice of economic globalization. Pedagogy, Culture and Society, 9, 59-77

Farrell, L. (2006). Making knowledge common: Literacy and knowledge at work. London: Routledge.

Farrell, L. and Fenwick, T. (2007). Educating a global workforce? In Farrell, L. and Fenwick, T. (Eds.) Educating the global workforce. Routledge.

HRSDC (n.d.a). Essential skills. Ottawa, ON: Human Resources and Skills Development of Canada. http://www.hrsdc.gc.ca/en/hip/hrp/essential_skills/essential_skills_index.shtml

HRSDC. (n.d.b.) Workplace Skills Strategy Overview. Human Resources and Skills Development Canada. http://www.hrsdc.gc.ca/en/workplaceskills/overview.shtml Retrieved on March 24, 2007.

HRDC (2002). Knowledge matters: Skills and learning for Canadians: Canada's innovation strategy. Ottawa, ON: Human Resource Development Canada (Document SP-482-02-02).

Huckin, T. (1997). Critical discourse analysis. In T. Miller (ed.) Functional approaches to written text: Classroom applications. Washington: US Information Service. 
Janks, H. (1997). Critical discourse analysis as a research tool. Discourse: Studies in the Cultural Politics of Education, 18, pp 329-343.

Kenway, J., Bullen, E., Simon, R. (2006). Haunting the knowledge economy. Taylor and Francis.

Lloyd, C. and Payne, J. (2003). The political economy of skill and the limits of educational policy. Journal of Education Policy, 18 (1), 85 - 107.

McGrath, R.G. (2001). Exploratory learning, innovative capacity and managerial oversight. Academy of Management Journal, 44 (1), 118-131.

McKenna, B. (2004) Critical discourse studies - where to from here? Critical Discourse Studies 1(1), 9-39.

Metcalfe A and Fenwick T. (2009). Knowledge for whose society? Knowledge production, higher education, and federal policy in Canada. Higher Education.

Nelson, B. (2003b) Our universities: Backing Australia's future. Canberra:

Commonwealth of Australia. Also available at: www.backingaustraliasfuture.gov.au/ policy_paper/policy_paper.pdf

Payne, J. (2000) The unbearable lightness of skill: The changing meaning of skill in UK policy discourses and some implications for education and training. Journal of Educational Policy, $15(3)$.

OECD (1996). The knowledge based economy. Paris: OECD.

Olssen, M. \& Peters, M.A. (2005). Neoliberalism, higher education and the knowledge economy: from the free market to knowledge capitalism. Journal of Education Policy, $20(3), 313-345$.

Robertson, S. L. (2005). Re-imagining and re-scripting the future of education: global knowledge economy discourses and the challenge to education systems. Comparative Education, (41) 2, 151-170.

Sawchuk, P. (2007). In L. Farrell and T. Fenwick (Eds.), Educating the global workforce. London: Routledge.

Stiglitz, J.E. (2002). Globalization and its discontents. New York/London: Norton.

Thompson, P., Warhurst, C. and Callaghan, G. (2001). Ignorant theory and

knowledgeable workers: Interrogating the connections between knowledge, skills and services. Journal of Management Studies 38(7), 923-942.

Tikly, L. (2001). Globalisation and education in the postcolonial world: Towards a conceptual framework. Comparative Education, 37 (22), 151-171. 
Valentin, C. (2005). Essential Skills and VET: Towards a critical role for HRD. Paper presented to the Researching Work and Learning Conference, University of Technology-Sydney,

December 2005.

Žižek, S. (2008). In defence of lost causes. London: Verso Books. 